\title{
RESISTÊNCIA NATURAL DE NOVE MADEIRAS DO SEMIÁRIDO BRASILEIRO A FUNGOS XILÓFAGOS EM SIMULADORES DE CAMPO ${ }^{1}$
}

Juarez Benigno Paes², Verlândia de Medeiros Morais ${ }^{3}$, Carlos Roberto de Lima² e Gilvan José Campelo dos Santos²

\begin{abstract}
RESUMO - Os objetivos desta pesquisa foram avaliar a resistência de nove madeiras de ocorrência no semiárido brasileiro a fungos xilófagos em simuladores de campo e relacionar a resistência natural com a densidade e teor de substâncias extraídas em água quente. As madeiras estudadas foram algaroba (Prosopis juliflora), angicovermelho (Anadenanthera colubrina var. cebil), aroeira (Myracrodruon urundeuva), braúna (Schinopsis brasiliensis), cássia (Senna siamea), craibeira (Tabebuia aurea), cumaru (Amburana cearensis), pau-d'arco (Tabebuia impetiginosa) e pereiro (Aspidosperma pyrifolium). De cada espécie foram retirados corpos-deprova de $0,5 \times 1,5 \times 15,0 \mathrm{~cm}$, com a maior dimensão na direção das fibras, em quatro posições na direção medula-casca do tronco. As amostras permaneceram por 180 dias sob ação da microflora natural existente em três tipos de solos: de floresta, de uso agrícola e com gramíneas. Em todas as madeiras ensaiadas, a resistência ao apodrecimento foi afetada pela posição na direção medula-casca. Apenas na aroeira a resistência da madeira esteve associada à sua densidade e à quantidade de extrativos solúveis em água quente. A resistência das madeiras de algaroba, angico, craibeira e pau-d' arco não esteve associada à densidade nem ao teor de extrativos. O alburno foi a posição mais atacada em todos os solos analisados. Entre os solos testados, o de uso agrícola apresentou menos atividade biológica, deteriorando menos as madeiras testadas.
\end{abstract}

Palavras-chave: Madeiras do semiárido, resistência natural e simulador de campo.

\section{NATURAL RESISTANCE OF NINE WOODS FROM THE BRAZILIAN SEMI- ARID REGION TO WOOD-DESTROYING FUNGI IN FIELD SIMULATORS}

\begin{abstract}
The objectives of this research were to evaluate the natural resistance of nine woods from the Brazilian semi-arid region to fungi under field simulator condition and to correlate the wood natural resistance with the wood density and the content of extractives soluble in hot water. The studied woods were Prosopis juliflora, Anadenanthera colubrina var. cebil, Myracrodruon urundeuva, Schinopsis brasiliensis, Senna siamea, Tabebuia aurea, Amburana cearensis, Tabebuia impetiginosa and Aspidosperma pyrifolium. Test samples measuring $0.5 \times 1.5 \times 15.0 \mathrm{~cm}$, with the largest measure taken on fiber direction, were obtained from four positions on pith to bark direction in the stem. The samples were submitted to the action of natural microflora of three soils; forest, agricultural use and gramineous plant soils, for 180 days. Wood resistance to decay was affected by the bark-heart wood position. Just for M. urundeuva, the wood resistance was associated to wood density and extractives content soluble in hot water. The resistance of $\boldsymbol{P}$. juliflora, A. columbrina, T. aurea, and T. impetiginosa woods was not associated to density nor the extractive content. The sp-wood was the most attacked position for all soils. Among the tested soils, the one for agricultural use presented the lowest biological activity, presenting lower deterioration for the tested woods.
\end{abstract}

Keywords: Brazilian semi-arid woods, wood natural resistance and field simulator.

\footnotetext{
${ }^{1}$ Recebido em 20.08.2007 e aceito para publicação em 24.04.2009.

${ }^{2}$ Unidade Acadêmica de Engenharia Florestal da Universidade Federal de Campina Grande (UFCG). E-mail: <jbp2@uol.com.br>, <crlima16@hotmial.com>,<gilcampeloapae@ig.com.br>.

${ }^{3}$ Programa de Pós-Graduaçãoem Fitotecniada UniversidadeFederal Rural doSemi-Árido(UFERSA).E-mail: <verlandiamorais@yahoo.com.br>.
} 


\section{INTRODUÇÃO}

O semiárido brasileiro abrange uma área de 1.150.662 $\mathrm{km}^{2}$, que corresponde a 74,30\% da Região Nordeste e a $13,52 \%$ da superfície do Brasil (PNUD/FAO/IBAMA/ Gov. Paraíba, 1994). A vegetação do semiárido (Caatinga) é composta de uma variedade de espécies arbustivas e arbóreas que apresentam potencial pouco conhecido cientificamente.

A madeira apresenta uma gama variável de utilização, tanto no meio rural quanto urbano. Porém, em virtude da sua estrutura anatômica e constituição química, sofre o ataque de vários organismos deterioradores, sendo os fungos os responsáveis pelos maiores danos causados à madeira (HUNT e GARRATT, 1967; CAVALCANTE, 1982; CARBALLEIRA LOPEZ e MILANO, 1986).

A constituição química da madeira é bastante variável entre espécies e até mesmo entre partes de uma mesma planta, o que determina sua resistência ao ataque de organismos biológicos, sendo o cerne mais resistente que o alburno(CARBALLEIRALOPEZe MILANO, 1986).

A resistência natural da madeira a organismos xilófagos também é afetada pelas condições de uso, sendo mais bem avaliada quando a madeira é utilizada em condições reais (testes de campo), em que é exposta aos agentes físicos, químicos e biológicos do solo. Assim, o conhecimento da resistência natural da madeira é de fundamental importância para que se possa recomendar o seu emprego adequado, evitar gastos desnecessários com a reposição de peças deterioradas e reduzir os impactos sobre as árvores remanescentes.

Esta pesquisa teve como objetivos avaliar a resistência natural de nove madeiras de ocorrência no semiárido brasileiro a várias classes de fungos, em simuladores de campo e relacionar a resistência natural com a densidade das madeiras e com o teor de substâncias extraídas em água quente.

\section{MATERIAL E MÉTODOS}

\subsection{Espécies Estudadas e Confecção dos Corpos-de-Prova}

$\mathrm{Na}$ pesquisa foram empregadas nove espécies madeireiras, sendo sete de ocorrência natural no semiárido e duas exóticas (algaroba e cássia) aclimatadas na Região Nordeste (Tabela 1).

As espécies testadas, com exceção da algaroba e da cássia que foram colhidas no Campus da Universidade Federal de Campina Grande (UFCG), em Patos, PB, foram adquiridas em serrarias no mesmo município.

As toras selecionadas foram transformadas em pranchões de $\pm 8 \mathrm{~cm}$ de espessura, que continham o cerne e o alburno intactos. Posteriormente, os pranchões foram desdobrados em vigotas, que foram retiradas em quatro posições na direção medula-casca ( 1 - posição interna - cerne interno, 2 - posição mediana-interna - cerne, 3 - posição mediana externa - cerne externo e 4 - posição externa - alburno), como demonstrado na Figura 1. Desse modo, representou-se toda a madeira e não apenas o cerne (posições 1, 2 e 3), como preconizado por Willeitner (1984), ou a posição 3, segundo "American Society for Testing and Materials" - ASTM D - 2017 (ASTM, 1994c).

As vigotas foram transformadas em corpos-deprova de 0,5 x 1,5 x 15,0 cm (largura x espessura $\mathrm{x}$ comprimento), a fim de representar as variações na resistência da madeira e caracterizar as posições mais resistentes aos fungos xilófagos existentes em solos de três locais e usos diferentes, no Município de Patos, PB.

Tabela 1 - Relação das espécies estudadas

Table 1 - List of the studied species

\begin{tabular}{ll}
\hline Nome Comum & \multicolumn{1}{c}{ Nome Científico } \\
\hline Algaroba & Prosopis juliflora (Sw.) DC. \\
Angico-vermelho & Anadenanthera colubrina (Vell.) Breman. var. cebil (Gris.) Alts. \\
Aroeira & Myracrodruon urundeuva Allemão \\
Braúna & Schinopsis brasiliensis Engl. \\
Cássia & Senna siamea (Lam.) H.S. Irwin \& Barneby \\
Craibeira & Tabebuia aurea (Silva Manso) Benth. \& Hook. f. ex S. Moore \\
Cumaru & Amburana cearensis (Allemão) A.C.Sm. \\
Pau-D’arco & Tabebuia impetiginosa (Mart.) Standl. \\
Pereiro & Aspidosperma pyrifolium Mart. \\
\hline
\end{tabular}

R. Árvore, Viçosa-MG, v.33, n.3, p.511-520, 2009 


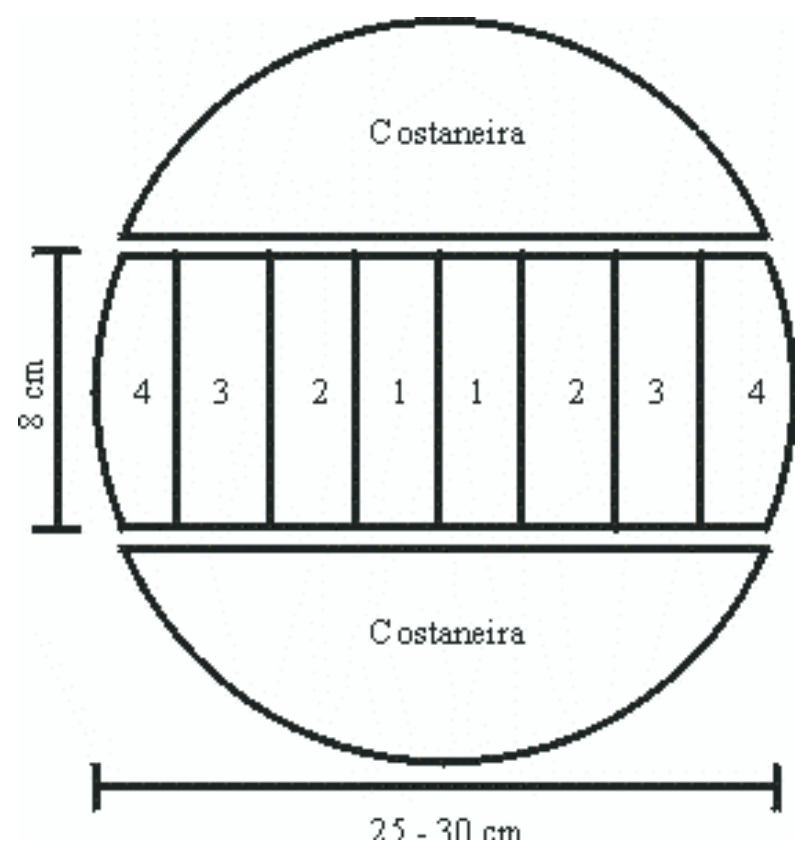

Figura 1 - Obtenção das seções para confecção dos corposde-prova.

Figure 1-Achievement of the sections for test sample fabrication.

Selecionaram-se amostras isentadas de defeitos, as quais foram identificadas em função da espécie, posição na árvore e repetição. Além das espécies a serem testadas, foram utilizadas como padrão de comparação (BECKER, 1970; ASTM, 1994b) amostras de Pinus sp.

Os corpos-de-prova selecionados foram secos em estufa a $103 \pm 2{ }^{\circ} \mathrm{C}$ até massa constante. Mediramse a massa e o volume de cada amostra, conforme o recomendado pela ASTM D - 1413 (ASTM, 1994b); os valores mensurados foram utilizados no cálculo da densidade anidra da madeira e, também da perda de massa causada pelos fungos dos solos testados.

\subsection{Determinação do Teor de Extrativos em Água Quente}

As amostras não selecionadas para o ensaio foram transformadas em cavacos, com dimensões semelhantes a palitos de fósforos, e convertidas em serragem em moinho do tipo Willey. A serragem foi peneirada, e utilizou-se a que passou pela peneira de 40 "meshes" e ficou retida na de 60 "meshes".

Para a determinação dos extrativos foram seguidas as recomendações da norma ASTM D - 1110 (ASTM, 1994a), que padroniza o teste de solubilidade da madeira em água quente. Foram utilizados 2,0 g de serragem, absolutamente seca, a qual foi mantida sob extração por 3 h na temperatura de ebulição da água. Após a extração, as amostras foram filtradas em cadinhos de porosidade 2 .

As amostras foram lavadas (cinco vezes) com água destilada quente e secas em estufa à temperatura de $103 \pm 2{ }^{\circ} \mathrm{C}$, por $24 \mathrm{~h}$, sendo a sua massa medida em balança de $0,1 \mathrm{mg}$ de precisão. Todas as extrações foram realizadas em duplicatas.

\subsection{Resistência da Madeira em Simulador Acelerado de Campo}

Para montagem dos simuladores foram seguidas as recomendações de Vinden et al. (1982) e Paes (1997).

Este ensaio foi montado com solos ao natural provenientes de três diferentes locais e usos: solo com cobertura de floresta nativa, solo com gramíneas e solo de cultivo agrícola. Nos locais de coletas de cada solo, foram retiradas amostras nos horizontes A e B, a fim de representar as características físico-químicas e biológicas dos solos de cada local (Tabela 2).

As amostras provenientes de cada horizonte foram peneiradas, ao ser utilizada para o solo de horizonte A, peneira com malha de $0,4 \times 0,4 \mathrm{~cm}$ e para o solo de horizonte $\mathrm{B}$, malha de $1,5 \times 1,5 \mathrm{~cm}$. Os ensaios foram montados em caixas (simuladores) com dimensões de 50 x 60 × $60 \mathrm{~cm}$ (menor dimensão na direção da largura), confeccionadas de compensado. Foram feitos dois orifícios de $2 \mathrm{~cm}$ de diâmetro, em duas faces do simulador (largura do simulador) para possibilitar a drenagem. Os orifícios distanciaram de aproximadamente $15 \mathrm{~cm}$ da extremidade e a uma altura de $15 \mathrm{~cm}$ do fundo do simulador.

As caixas foram revestidas com lona impermeável e receberam quatro drenos. Para o preenchimento dos simuladores, utilizaram-se cascalhos e solos. Os primeiros $15 \mathrm{~cm}$ (altura dos drenos) foram preenchidos com cascalho, em seguida completados pelos respectivos solos, tendo o horizonte B uma altura de $25 \mathrm{~cm}$ e o horizonte $\mathrm{A}, 10 \mathrm{~cm}$.

Nas caixas (simuladores de campo) foram parcialmente soterradas (2/3 do comprimento) amostras (estacas com dimensões de 0,5 x 1,5 x 15,0 cm), aleatoriamente distribuídas no simulador. Os simuladores foram umedecidos semanalmente para manter a umidade próxima à capacidade de campo dos solos empregados.

R. Árvore, Viçosa-MG, v.33, n.3, p.511-520, 2009 
Tabela 2 - Características químicas dos solos utilizados Table 2-Chemical characteristics of the soils used

\begin{tabular}{|c|c|c|c|c|c|c|c|c|c|}
\hline \multirow[t]{2}{*}{ Solos } & \multirow{2}{*}{$\frac{\mathrm{pH}}{\left(\mathrm{CaCl}_{2}\right)}$} & $\mathrm{Ca}^{+2}$ & $\mathrm{Mg}^{+2}$ & $\mathrm{~K}^{+}$ & $\mathrm{Na}^{+}$ & $\mathrm{H}^{+}+\mathrm{Al}^{+3}$ & CTC & $\mathrm{V}$ & M.O. \\
\hline & & \multicolumn{5}{|c|}{$\left(\mathrm{cmolc} / \mathrm{cm}^{3}\right)$} & \multicolumn{2}{|c|}{$(\%)$} & $\left(\mathrm{g} / \mathrm{dm}^{3}\right)$ \\
\hline$\overline{\text { Floresta A }}$ & 7,1 & 10,0 & 1,8 & 0,84 & 4,0 & 0,9 & 17,5 & 94 & 7,55 \\
\hline Floresta B & 7,3 & 10,5 & 2,0 & 0,70 & 4,0 & 1,0 & 18,2 & 94 & 7,24 \\
\hline Agrícola A & 6,1 & 7,2 & 1,3 & 0,30 & 2,4 & 1,1 & 11,1 & 90 & 7,24 \\
\hline Agrícola B & 6,1 & 7,2 & 1,2 & 0,95 & 2,3 & 1,0 & 11,7 & 92 & 6,21 \\
\hline Gramínea A & 6,9 & 8,4 & 2,0 & 0,18 & 0,9 & 1,1 & 10,9 & 90 & 5,90 \\
\hline Gramínea B & 6,7 & 8,7 & 1,5 & 0,20 & 1,0 & 1,5 & 11,9 & 88 & 9,31 \\
\hline
\end{tabular}

CTC = Capacidade de Troca de Catiônica; V = Saturação por Base; e MO = Matéria Orgânica.

Os simuladores foram mantidos em sala climatizada ( $27 \pm 1{ }^{\circ} \mathrm{C}$ e $75 \pm 5 \%$ de umidade relativa), para acelerar a degradação biológica das madeiras. O ensaio foi avaliado depois de decorridos 180 dias.

Depois de desativado o experimento, os corposde-prova foram retirados das caixas e limpos com escova de cerdas macias e secos em estufa à temperatura de $103 \pm 2{ }^{\circ} \mathrm{C}$ até massa constante. As amostras foram pesadas e a atividade fúngica, avaliada por meio da perda de massa e do desgaste (nota) sofrido em função da atividade biológica (Tabela 3).

\subsection{Análise e Avaliação dos Resultados}

Para comparar a resistência natural das madeiras estudadas, foi empregado o delineamento em blocos casualizados com arranjo fatorial, em que foram analisados os seguintes fatores: solos, com três níveis; madeiras, com nove níveis; posição na direção medulacasca, com quatro níveis; e blocos, com cinco níveis.

Para possibilitar a análise estatística, os dados de perda de massa foram transformados em arcsen [raiz (perda de massa/100)]. Essa transformação sugerida por Steel e Torrie (1980), foi necessária para permitir a homogeneidade das variâncias. Na análise e avaliação dos resultados foi empregado o teste de Tukey a 5\% de probabilidade, para os fatores e interação detectados como significativos pelo teste de F. Além disso, estabeleceram-se correlações entre a perda de massa e a densidade da madeira e, também, entre a perda de massa e o teor de extrativo, por meio da correlação de Pearson e de teste de t a $5 \%$ de probabilidade.

Os valores do desgaste sofrido pela madeira (nota) foram utilizados para auxiliarem as interpretações dos resultados.

R. Árvore, Viçosa-MG, v.33, n.3, p.511-520, 2009
Tabela 3 - Avaliação de ensaio de campo Table 3 - Field test evaluation (Becker, 1970)

\begin{tabular}{lcc}
\hline Estado de Sanidade & Nota & Índice de Comportamento \\
\hline Sadio & 0 & 100 \\
Ataque superficial & 1 & 90 \\
Ataque moderado & 2 & 70 \\
Ataque intenso & 3 & 40 \\
Quebra & 4 & 0 \\
\hline
\end{tabular}

Fonte: BECKER, 1970.

\section{RESULTADOS E DISCUSSÃO}

Os valores médios da densidade das madeiras ( $\mathrm{g}$ / $\mathrm{cm}^{3}$ ), do teor de extrativos solúveis em água quente e da média da perda de massa (\%) e as correlações entre perda de massa e densidade e entre perda de massa e teor de extrativos encontram-se no Tabela 4.

Observa-se, na Tabela 4, que apenas a aroeira apresentou correlação significativa entre a resistência da madeira (perda de massa) para ambos os fatores (densidade e extrativos em água quente).

No cumaru e pereiro, observou-se correlação significativa entre a perda de massa e a densidade. No primeiro, o incremento na densidade causou diminuição na perda de massa, ou seja, a resistência da madeira aumentou com a densidade. No entanto, no pereiro o incremento na densidade provocou aumento na perda de massa, ou seja, a resistência da madeira diminuiu com a densidade. Nessas madeiras não foi observada correlação significativa entre a perda de massa e o teor de extrativos. As madeiras de braúna e cássia não apresentaram correlação significativa entre a densidade e a perda de massa. No entanto, a resistência da madeira aumentou com o teor de extrativos. $\mathrm{Na}$ algaroba, angico, craibeira e pau d' arco não foram notadas correlações significativas entre a densidade 
e a resistência das madeiras (perda de massa). Resultados semelhantes foram constatados em relação ao teor de substâncias extraídas em água quente.

Os valores médios da perda de massa (\%) e do desgaste sofrido pelos corpos-de-prova em cada tipo de solo encontram-se na Tabela 5.

As madeiras que apresentaram as maiores perdas de massa foram aroeira, braúna, cássia e cumaru, todas na posição 4, com valores de 17,$55 ; 22,28 ; 16,33$; e $35,45 \%$ (solo de floresta) e de 12,$38 ; 12,47 ; 15,11$; e $35,88 \%$ (solo com gramíneas), respectivamente; a aroeira e o cumaru (posição 4) e cássia (posições 3 e 4), com valores de 13,11 e 30,26 ; e 13,71 , e $13,14 \%$, respectivamente
( solo de uso agrícola). As madeiras de cumaru (todas as posições), nos solos de floresta e com gramíneas e cássia (posições 2, 3 e 4) em todos os solos analisados, apresentaram, de modo geral, as maiores perdas de massa.

As maiores resistências aos xilófagos encontrados nos solos foram observadas nas madeiras de aroeira (posições 2), com 2,95; 1,58; e 2,70\%; e pereiro (posições 2 e 3 ), $\operatorname{com} 2,78$ e 2,13; 2,36 e 1,77; e 2,28 e 1,62\% (solo de floresta, de uso agrícola e com gramíneas, respectivamente). A madeira de pereiro apresentou, de modo geral, as menores perdas de massa, em todas as posições analisadas.

Tabela 4 - Valores médios da densidade $\left(\mathrm{g} / \mathrm{cm}^{3}\right)$, do teor de extrativos $(\%)$, da perda de massa média (\%) e correlações entre perda de massa $\mathrm{x}$ densidade e perda de massa e extrativos das espécies estudadas

Table 4 - Mean values of wood density $\left(\mathrm{g} / \mathrm{cm}^{3}\right)$, extractive content $(\%)$ and weight loss $(\%)$ and the correlations between weight loss $x$ density and weight loss $x$ extractives for the studied species

\begin{tabular}{|c|c|c|c|c|c|c|}
\hline Espécies & $\begin{array}{c}\text { Posições } \\
\text { no Tronco }\end{array}$ & $\begin{array}{c}\text { Densidade } \\
\left(\mathrm{g} / \mathrm{cm}^{3}\right)\end{array}$ & $\begin{array}{c}\text { Extrativos em } \\
\mathrm{H}_{2} \mathrm{O} \text { Quente } \\
(\%)\end{array}$ & $\begin{array}{c}\text { Perda de } \\
\text { Massa Média } \\
(\%)\end{array}$ & $\begin{array}{c}\text { Perda de } \\
\text { Massa } \\
\mathbf{x} \\
\text { Densidade }\end{array}$ & $\begin{array}{c}\text { Perda de } \\
\text { Massa } \\
\mathbf{x} \\
\text { Extrativos }\end{array}$ \\
\hline 1 - Algaroba & $\begin{array}{l}\text { 1-Interna } \\
\text { 2-Med-Int } \\
\text { 3-Med-Ext } \\
\text { 4-Externa }\end{array}$ & $\begin{array}{l}0,83 \\
0,87 \\
0,88 \\
0,95\end{array}$ & $\begin{array}{l}5,67 \\
4,79 \\
4,93 \\
5,63\end{array}$ & $\begin{array}{l}6,07 \\
5,73 \\
4,97 \\
7,56\end{array}$ & $0,66^{\mathrm{ns}}$ & $0,72^{\mathrm{ns}}$ \\
\hline 2 - Angico & $\begin{array}{l}\text { 1-Interna } \\
\text { 2-Med-Int } \\
\text { 3-Med-Ext } \\
\text { 4-Externa }\end{array}$ & $\begin{array}{l}0,79 \\
0,78 \\
0,80 \\
0,81 \\
\end{array}$ & $\begin{array}{l}7,23 \\
7,28 \\
9,60 \\
7,09 \\
\end{array}$ & $\begin{array}{l}7,03 \\
4,71 \\
4,15 \\
8,23 \\
\end{array}$ & $0,51^{\mathrm{ns}}$ & $-0,70^{\mathrm{ns}}$ \\
\hline 3 - Aroeira & $\begin{array}{l}\text { 1-Interna } \\
\text { 2-Med-Int } \\
\text { 3-Med-Ext } \\
\text { 4-Externa }\end{array}$ & $\begin{array}{l}1,11 \\
1,09 \\
1,09 \\
0,94\end{array}$ & $\begin{array}{r}17,61 \\
17,23 \\
18,73 \\
8,05 \\
\end{array}$ & $\begin{array}{r}3,58 \\
2,41 \\
3,21 \\
14,35 \\
\end{array}$ & $-0,98 * *$ & $-0,98 * *$ \\
\hline 4 - Braúna & $\begin{array}{l}\text { 1-Interna } \\
\text { 2-Med-Int } \\
\text { 3-Med-Ext } \\
\text { 4-Externa }\end{array}$ & $\begin{array}{l}1,16 \\
1,11 \\
1,11 \\
1,09\end{array}$ & $\begin{array}{r}16,51 \\
22,66 \\
21,41 \\
3,79 \\
\end{array}$ & $\begin{array}{r}3,89 \\
2,45 \\
2,74 \\
14,25 \\
\end{array}$ & $-0,52^{\mathrm{ns}}$ & $-0,98 * *$ \\
\hline 5 - Cássia & $\begin{array}{l}\text { 1-Interna } \\
\text { 2-Med-Int } \\
\text { 3-Med-Ext } \\
\text { 4-Externa }\end{array}$ & $\begin{array}{l}0,99 \\
1,02 \\
1,07 \\
0,77\end{array}$ & $\begin{array}{r}12,73 \\
11,24 \\
7,61 \\
5,43 \\
\end{array}$ & $\begin{array}{r}6,97 \\
11,30 \\
13,95 \\
14,86 \\
\end{array}$ & $-0,37^{\mathrm{ns}}$ & $-0,93 *$ \\
\hline 6 - Craibeira & $\begin{array}{l}\text { 1-Interna } \\
\text { 2-Med-Int } \\
\text { 3-Med-Ext } \\
\text { 4-Externa }\end{array}$ & $\begin{array}{l}0,66 \\
0,63 \\
0,68 \\
0,68\end{array}$ & $\begin{array}{l}3,83 \\
3,38 \\
3,51 \\
4,91 \\
\end{array}$ & $\begin{array}{l}9,26 \\
7,60 \\
6,83 \\
8,65\end{array}$ & $0,01^{\mathrm{ns}}$ & $0,55^{\mathrm{ns}}$ \\
\hline 7 - Cumaru & $\begin{array}{l}\text { 1-Interna } \\
\text { 2-Med-Int } \\
\text { 3-Med-Ext } \\
\text { 4-Externa }\end{array}$ & $\begin{array}{l}0,58 \\
0,56 \\
0,53 \\
0,49\end{array}$ & $\begin{array}{l}11,94 \\
25,39 \\
15,14 \\
19,60\end{array}$ & $\begin{array}{l}10,79 \\
10,26 \\
15,42 \\
33,86\end{array}$ & $-0,93 *$ & $0,10^{\mathrm{ns}}$ \\
\hline 8 - Pau D'arco & $\begin{array}{l}\text { 1-Interna } \\
\text { 2-Med-Int } \\
\text { 3-Med-Ext } \\
\text { 4-Externa }\end{array}$ & $\begin{array}{l}1,01 \\
0,96 \\
0,95 \\
0,90\end{array}$ & $\begin{array}{l}7,91 \\
7,71 \\
7,79 \\
7,58\end{array}$ & $\begin{array}{r}5,07 \\
3,69 \\
7,25 \\
11,64 \\
\end{array}$ & $-0,81^{\mathrm{ns}}$ & $-0,66^{\mathrm{ns}}$ \\
\hline 9 - Pereiro & $\begin{array}{l}\text { 1-Interna } \\
\text { 2-Med-Int } \\
\text { 3-Med-Ext } \\
\text { 4-Externa }\end{array}$ & $\begin{array}{l}0,80 \\
0,79 \\
0,76 \\
0,80\end{array}$ & $\begin{array}{l}3,21 \\
3,66 \\
4,93 \\
4,71\end{array}$ & $\begin{array}{l}3,57 \\
2,47 \\
1,84 \\
3,80\end{array}$ & $0,91 *$ & $-0,32^{\mathrm{ns}}$ \\
\hline
\end{tabular}

** Significativo a $1 \%$; Significativo a 5\%; e ${ }^{\text {ns }}$ Não significativo a 5\% de probabilidade, pelo teste de t. 
Tabela 5 - Valores da perda de massa $(\%)$ dos solos de floresta, agrícola e com gramíneas Table 5 - Mean values of weight loss (\%) for the forest, agricultural and gramineous plant soils

\begin{tabular}{|c|c|c|c|c|c|c|c|}
\hline \multirow[t]{3}{*}{ Espécies } & \multirow{3}{*}{$\begin{array}{c}\text { Posições } \\
\text { no } \\
\text { Tronco }\end{array}$} & \multicolumn{6}{|c|}{$\begin{array}{c}\text { Perda de Massa - PPM (\%) e Desgaste (Nota) dos Solos } \\
\text { Testados }\end{array}$} \\
\hline & & \multicolumn{2}{|c|}{ Floresta } & \multicolumn{2}{|c|}{ Agrícola } & \multicolumn{2}{|c|}{ Gramíneas } \\
\hline & & PPM & Nota & PPM & Nota & PPM & Nota \\
\hline \multirow{4}{*}{1 - Algaroba } & 1-Interna & 7,40 & 0,80 & 5,30 & 0,76 & 5,51 & 0,80 \\
\hline & 2-Med-Int & 7,00 & 0,32 & 4,99 & 0,48 & 5,19 & 0,28 \\
\hline & 3-Med-Ext & 5,42 & 0,32 & 4,07 & 0,60 & 5,43 & 0,36 \\
\hline & 4-Externa & 7,80 & 0,60 & 6,20 & 0,76 & 8,67 & 0,56 \\
\hline \multirow{4}{*}{2 - Angico } & 1-Interna & 9,14 & 0,88 & 5,25 & 0,84 & 6,73 & 0,60 \\
\hline & 2-Med-Int & 5,56 & 0,28 & 3,63 & 0,56 & 4,94 & 0,68 \\
\hline & 3-Med-Ext & 4,60 & 0,40 & 4,49 & 0,72 & 3,36 & 0,64 \\
\hline & 4-Externa & 8,04 & 0,68 & 6,54 & 1,00 & 10,12 & 0,80 \\
\hline \multirow{4}{*}{3 - Aroeira } & 1-Interna & 3,93 & 0,68 & 2,89 & 0,36 & 3,93 & 0,40 \\
\hline & 2-Med-Int & 2,95 & 0,20 & 1,58 & 0,20 & 2,70 & 0,20 \\
\hline & 3-Med-Ext & 3,11 & 0,44 & 2,47 & 0,24 & 4,06 & 0,56 \\
\hline & 4-Externa & 17,55 & 3,16 & 13,11 & 2,80 & 12,38 & 1,16 \\
\hline \multirow{4}{*}{4 - Braúna } & 1-Interna & 4,76 & 0,92 & 3,20 & 0,80 & 3,70 & 1,00 \\
\hline & 2-Med-Int & 3,01 & 0,44 & 1,67 & 0,44 & 2,68 & 0,96 \\
\hline & 3-Med-Ext & 3,20 & 0,92 & 2,10 & 0,36 & 2,91 & 0,76 \\
\hline & 4-Externa & 22,28 & 2,48 & 7,99 & 1,36 & 12,47 & 1,08 \\
\hline \multirow{4}{*}{5 - Cássia } & 1-Interna & 6,64 & 1,00 & 6,36 & 1,08 & 7,92 & 1,32 \\
\hline & 2-Med-Int & 10,42 & 1,08 & 12,12 & 1,16 & 11,36 & 1,00 \\
\hline & 3-Med-Ext & 14,32 & 1,20 & 13,71 & 1,28 & 13,83 & 1,32 \\
\hline & 4-Externa & 16,33 & 1,36 & 13,14 & 1,00 & 15,11 & 0,96 \\
\hline \multirow{4}{*}{6 - Craibeira } & 1-Interna & 11,22 & 1,16 & 6,27 & 1,08 & 10,30 & 0,84 \\
\hline & 2-Med-Int & 8,28 & 1,40 & 7,30 & 1,76 & 7,23 & 1,04 \\
\hline & 3-Med-Ext & 7,85 & 1,04 & 6,41 & 1,08 & 6,23 & 0,92 \\
\hline & 4-Externa & 10,38 & 1,32 & 6,50 & 1,08 & 9,07 & 1,20 \\
\hline \multirow{4}{*}{7 - Cumaru } & 1-Interna & 11,54 & 1,28 & 8,65 & 0,96 & 12,19 & 1,36 \\
\hline & 2-Med-Int & 10,93 & 1,08 & 9,28 & 0,92 & 10,57 & 0,92 \\
\hline & 3-Med-Ext & 15,64 & 1,36 & 10,98 & 0,96 & 19,65 & 1,88 \\
\hline & 4-Externa & 35,45 & 3,80 & 30,26 & 3,12 & 35,88 & 4,00 \\
\hline \multirow{4}{*}{8 - Pau-D'arco } & 1-Interna & 6,44 & 0,56 & 4,12 & 0,28 & 4,65 & 0,88 \\
\hline & 2-Med-Int & 4,19 & 0,12 & 3,86 & 0,16 & 3,01 & 0,36 \\
\hline & 3-Med-Ext & 8,48 & 0,72 & 6,47 & 0,72 & 6,81 & 0,64 \\
\hline & 4-Externa & 13,42 & 1,76 & 9,34 & 1,12 & 12,17 & 1,00 \\
\hline \multirow{4}{*}{9 - Pereiro } & 1-Interna & 3,91 & 0,44 & 3,14 & 0,52 & 3,66 & 0,52 \\
\hline & 2-Med-Int & 2,78 & 0,32 & 2,36 & 0,40 & 2,28 & 0,32 \\
\hline & 3-Med-Ext & 2,13 & 0,16 & 1,77 & 0,20 & 1,62 & 0,24 \\
\hline & 4-Externa & 4,22 & 0,52 & 2,92 & 0,28 & 4,26 & 0,44 \\
\hline
\end{tabular}

A madeira de Pinus sp., de baixa resistência a xilófagos, utilizada como padrão de comparação (BECKER, 1970; ASTM, 1994b) sofreu perda de massa de 13,62; 6,86; e 10,97\%, no solo de floresta, agrícola e de gramíneas, respectivamente. Esses valores foram mais baixos que os de muitas das madeiras testadas. Isso, segundo Baines (1982), Johnson et al. (1982), Vinden et al. (1982), Drysdale (1984) e Mckaig (1985), está associado às condições em que são mantidos os simuladores, o que favorece o desenvolvimento e ataque de fungos causadores da padridão-mole, os quais são mais nocivos às madeiras de folhosas.

De modo geral, os maiores desgastes (notas) corresponderam às maiores perda de massa. Isso indica que o critério de notas, mesmo sendo subjetivo, quando bem avaliado, corresponde à resistência oferecida pelas madeiras.

A perda de massa e o desgaste variaram com a espécie, posições na madeira e solos empregados. A análise de variância da perda de massa (\%) mostrou que os fatores posição, espécie, solo e as interações de primeira e segunda ordens foram significativos pelo teste de F, a $5 \%$ de probabilidade. As interações de primeira ordem foram desdobradas e analisadas pelo teste de tukey ( $\mathrm{p} £ 0,05$ ), sendo os resultados apresentados na Tabela 6.

Observa-se na Tabela 6, quanto ao efeito das espécies nas posições, na posição 1 que as espécies mais deterioradas foram cumaru e craibeira. As espécies, algaroba, angico, cássia e pau d'arco apresentaram 
perda de massa menor em relação às espécies cumaru e craibeira. As espécies menos atacadas pelos fungos foram aroeira, braúna e pereiro. O pau d'arco teve resistência intermediária entre as espécies algaroba, angico, cássia, aroeira, braúna e pereiro.

Na posição 2, observa-se que as madeiras mais atacadas foram as das espécies cássia e cumaru, seguidas pela craibeira e algaroba. Porém, esta última não diferiu estatisticamente do angico, que foi uma das espécies mais resistentes, a exemplo do pereiro, da braúna, da aroeira e do pau d' arco. Não houve diferença significativa entre as madeiras de pau d'arco e de angico.

Na posição 3, notou-se que as espécies menos deterioradas foram pereiro, braúna e aroeira. As madeiras de braúna e aroeira não diferiram do angico. As espécies mais atacadas foram cássia e cumaru, seguidas de pau d'arco, craibeira e algaroba. A madeira desta última sofreu deterioração semelhante à de angico.

Tabela 6 - Comparações múltiplas entre médias da perda de massa causada pelos fungos existentes nos solos Table 6 -Multiple comparisons among means for weight loss (\%) caused by fungi present in soils

\begin{tabular}{|c|c|c|c|c|}
\hline \multicolumn{5}{|c|}{ Efeito das Espécies nas Posições Analisadas } \\
\hline \multirow[b]{2}{*}{ Espécies Estudadas } & \multicolumn{4}{|c|}{ Posições na Madeira } \\
\hline & 1- Interna & 2 - Méd. Int & 3 - Méd. Ext & 4 - Externa \\
\hline 1 - Algaroba & $6,07 \mathrm{Ac}$ & $5,73 \mathrm{ABbc}$ & $4,97 \mathrm{Bcd}$ & $7,56 \mathrm{Ad}$ \\
\hline 2 - Angico & $7,04 \mathrm{Abc}$ & $4,71 \mathrm{Bcd}$ & 4,15 Bde & $8,23 \mathrm{Ad}$ \\
\hline 3 - Aroeira & $3,58 \mathrm{Bd}$ & $2,41 \mathrm{Ce}$ & $3,21 \mathrm{BCef}$ & $14,35 \mathrm{Abc}$ \\
\hline 4 - Braúna & $3,89 \mathrm{Bd}$ & $2,45 \mathrm{Ce}$ & 2,74 BCef & $14,25 \mathrm{Abc}$ \\
\hline 5 - Cássia & $6,97 \mathrm{Cc}$ & $11,30 \mathrm{Ba}$ & $13,95 \mathrm{Aa}$ & $14,86 \mathrm{Ab}$ \\
\hline 6 - Craibeira & $9,26 \mathrm{Aab}$ & $7,60 \mathrm{ABb}$ & $6,83 \mathrm{Bbc}$ & $8,65 \mathrm{ABd}$ \\
\hline 7 - Cumaru & $10,79 \mathrm{Ca}$ & $10,26 \mathrm{Ca}$ & $15,42 \mathrm{Ba}$ & $33,86 \mathrm{Aa}$ \\
\hline 8 - Pau-d'arco & $5,07 \mathrm{Ccd}$ & $3,69 \mathrm{Cde}$ & $7,25 \mathrm{Bb}$ & $11,64 \mathrm{Ac}$ \\
\hline 9 - Pereiro & 3,57 ABd & $2,47 \mathrm{BCe}$ & $1,84 \mathrm{Cf}$ & $3,80 \mathrm{Ae}$ \\
\hline \multicolumn{5}{|c|}{ Efeito das Espécies nos Solos Utilizados } \\
\hline Espécies & \multicolumn{2}{|l|}{1 - Floresta } & 2 - Agrícola & 3 - Gramíneas \\
\hline 1 - Algaroba & \multicolumn{2}{|l|}{ 6,91 Ade } & $5,14 \mathrm{Bcd}$ & 6,20 Acd \\
\hline 2 - Angico & \multicolumn{2}{|l|}{$6,84 \mathrm{Ae}$} & 4,98 Bcde & $6,29 \mathrm{ABcd}$ \\
\hline 3 - Aroeira & \multicolumn{2}{|l|}{$6,89 \mathrm{Ae}$} & 5,01 Bcde & $5,77 \mathrm{ABd}$ \\
\hline 4 - Braúna & \multicolumn{2}{|l|}{8,31 Acde } & $3,74 \mathrm{Cef}$ & $5,44 \mathrm{Bd}$ \\
\hline 5 - Cássia & \multicolumn{2}{|l|}{$11,93 \mathrm{Ab}$} & & $12,06 \mathrm{Ab}$ \\
\hline 6 - Craibeira & $9,43 \mathrm{Abc}$ & & & $8,21 \mathrm{Ac}$ \\
\hline 7 - Cumaru & $18,39 \mathrm{Aa}$ & & & $19,57 \mathrm{Aa}$ \\
\hline 8 - Pau-d'arco & 8,13 Acde & & & $6,66 \mathrm{Bcd}$ \\
\hline 9 - Pereiro & 3,26 Af & & & $2,96 \mathrm{Ae}$ \\
\hline
\end{tabular}

\begin{tabular}{l|c|c|c|c}
\hline \multicolumn{5}{c}{ Efeito dos Solos nas Posições das Madeiras } \\
\hline \multicolumn{1}{c}{ Solos } & \multicolumn{4}{c}{ Posições na Madeira } \\
\cline { 2 - 5 } & $1-$ Interna & $2-$ Méd. Int & $3-$ Méd. Ext & $4-$ Externa \\
\hline 1 - Floresta & $7,22 \mathrm{Ba}$ & $6,12 \mathrm{Ca}$ & $7,19 \mathrm{BCa}$ & $15,05 \mathrm{Aa}$ \\
2 - Agrícola & $5,02 \mathrm{Bb}$ & $5,20 \mathrm{Bb}$ & $5,83 \mathrm{Bb}$ & $10,67 \mathrm{Ac}$ \\
3 - Gramíneas & $6,51 \mathrm{Ba}$ & $5,55 \mathrm{Cab}$ & $7,10 \mathrm{Ba}$ & $13,35 \mathrm{Ab}$ \\
\hline
\end{tabular}

As médias seguidas na horizontal por uma mesma letra maiúscula e na vertical por uma mesma letra minúscula, em cada efeito, não diferem estatisticamente (Tukey; $\mathrm{p} \geq 0,05$ ). 
Verifica-se, na posição 4, que cumaru foi a madeira mais atacada, seguida da cássia, braúna, aroeira e pau d'arco. Etre as madeiras testadas, posição 4, a mais resistente foi o pereiro, seguida de craibeira, angico e algaroba.

O cumaru e cássia foram, entre as espécies analisadas, as mais deterioradas. Já o pereiro foi a menos atacada em todas as posições analisadas. No entanto, a braúna e a aroeira apresentaram o cerne (posições 1, 2 e 3) muito resistente e alburno (posição 4) perecível.

A análise do efeito das posições, em cada espécie (Tabela 6) revelou que algaroba, angico e pereiro apresentaram padrão de deterioração semelhante, em que as posições 1 e 4 foram as mais atacadas pelos organismos xilófagos, e a posição 3, aquela que sofreu menor ataque. A deterioração sofrida pelas madeiras de algaroba, angico e craibeira, nas posições 2 e 3, foi semelhante. Nessas madeiras, a deterioração causada nas posições 1 e 4 também foi semelhante. Na madeira de pereiro (posições 1 e 2 e 2 e 3 ) não foram observadas diferenças estatísticas.

A madeira de aroeira e braúna apresentaram maior resistência na posição 2 , tendo a posição 3 resistência intermediaria entre as posições 1 e 2 . A posição 4 (alburno) foi a mais deteriorada. Já no cumaru e pau d'arco as posições 1 e 2 foram as mais resistentes, diferindo das posições 3 e 4 . A exemplo das demais espécies, a posição 4 foi a mais deteriorada. A espécie cássia foi mais resistente na posição 1 ; e as posições 3 e 4 não diferiram entre si. Nessa espécie, a posição 2 apresentou comportamento intermediário, sendo mais resistente que as posições 3 e 4 e menor que a posição 1 .

A análise do efeito das espécies, em cada tipo de solo, revelou, no solo de floresta (solo 1) que a espécie mais resistente foi o pereiro, seguido da aroeira, angico, algaroba, braúna e pau d'arco. A madeira mais deteriorada foi o cumaru e, na seqüência, a cássia e a craibeira. A craibeira não diferiu significativamente da braúna, pau d'arco e cássia.

Observou-se, no solo de uso agrícola (solo 2), que o cumaru e a cássia foram as madeiras mais deterioradas. As espécies mais resistentes foram pereiro e braúna. As espécies craibeira, angico, aroeira, pau d'arco e algaroba não diferiram estatisticamente, apresentando comportamento intermediário entre as espécies mais resistentes e as mais deterioradas.
No solo com gramíneas (solo 3), novamente a espécie pereiro foi a mais resistente e a menos resistente, o cumaru, seguidas pela cássia e craibeira. Braúna, aroeira, pau d'arco, angico e algaroba não diferiram entre si e apresentaram comportamento intermediário entre as espécies mais deterioradas e as mais resistentes.

Nos três solos testados, a espécie mais atacada foi o cumaru, juntamente com a cássia, e as mais resistentes, o pereiro e a aroeira.

Ao analisar o efeito dos solos dentro de cada espécie, observou-se que as madeiras de algaroba, craibeira e cumaru sofreram ataque dos xilófagos, semelhantemente ao ocorrido nos três solos testados. Tendo os solos 1 (floresta) e 3 (gramíneas) provocado maior deterioração em relação ao solo 2 (agrícola).

As espécies cássia e pereiro sofreram ataques semelhantes dos organismos xilófagos nos três tipos de solos. Angico e aroeira foram mais deteriorados nos solos 1 e 3 , porém, não se observou diferença significativa entre a deterioração causada pelos organismos presentes nos solos 2 e 3 .

A madeira de braúna sofreu ataque diferenciado nos três solos testados, tendo o solo 1 causado maior deterioração que os solos 2 e 3 . Na madeira de pau d 'arco, notou-se que o solo de floresta causou maior deterioração que os solos com gramíneas e o de uso agrícola. Não houve diferença significativa entre os efeitos dos solos 2 e 3 .

A análise do efeito dos solos, nas posições das madeiras, revelou que o solo com cobertura florestal (solo 1) e o com gramínea ( solo 3) apresentaram maior atividade de organismos xilófagos, proporcionando maior deterioração às madeiras testadas que o solo 2 (agrícola). Isso ocorreu, provavelmente, porque os solos de floresta e com gramíneas estavam com cobertura vegetal, o que favorece o desenvolvimento de microrganismos, enquanto o solo de uso agrícola, por ser constantemente trabalhado e passar grande parte do tempo desprotegido, impede o desenvolvimento de organismos xilófagos e, consequentemente, há menor ataque às madeiras.

A análise do efeito das posições na madeira, em cada solo, indicou que nos três solos analisados (floresta, de uso agrícola e com gramíneas) a posição 4 foi a mais atacada pelos organismos xilófagos. No solo de floresta (solo 1), as posições 1 e 3 não diferiram entre

\section{R. Árvore, Viçosa-MG, v.33, n.3, p.511-520, 2009}


si. Também, não houve diferença significativa entre as posições 2 e 3 . Nos solos de uso agrícola, as posições 1,2 e 3 apresentaram perdas de massa semelhantes. No solo coberto com gramíneas, as posições 1 e 3 apresentaram perdas de massa superiores àquelas da posição 2 .

\section{CONCLUSÕES}

A alta resistência natural da madeira de aroeira está associada à sua densidade e quantidade de extrativos solúveis em água quente.

A resistência da madeira de cumaru aumenta com o incremento da densidade e a do pereiro diminui. A resistência dessas madeiras não está associada à quantidade de extrativos solúveis em água quente.

Na braúna e cássia, a resistência da madeira não está associada à densidade, no entanto aumenta com a quantidade de extrativos.

A densidade e a quantidade de substâncias extraídas em água quente não apresentam boa relação com a resistência das madeiras de algaroba, angico, craibeira e pau d'arco. Isso implica que a resistência dessas madeiras está relacionada a outras classes de extrativos que não são extraídos em água quente.

Em todas as madeiras ensaiadas, a resistência ao apodrecimento é afetada pela posição na direção medulacasca.

O cumaru e a cássia são, entre as espécies analisadas, as mais deterioradas e o pereiro, a mais resistente em todas as posições ensaiadas.

A análise do efeito das posições em cada solo indicou que nos três solos testados o alburno foi a posição mais atacada. Isso indica que, em locais de alto risco à deterioração, as madeiras devem ter o alburno removido, pois a sua baixa resistência compromete a estrutura.

Entre os solos testados, o de uso agrícola apresenta menor atividade biológica, deteriorando-se menos as madeiras testadas.

\section{REFERÊNCIAS}

AMERICAN SOCIETY FOR TESTING AND

MATERIALS - ASTM. Standard test methods for water solubility of wood. - ASTM D-1110.

Annual Book of ASTM Standard, v.410, p.195-196, 1994a.

\section{AMERICAN SOCIETY FOR TESTING AND}

MATERIALS - ASTM. Standard test methods for wood preservatives by laboratory soil-block cultures. ASTM D-1413. Annual Book of ASTM Standard, v.410, p.119-121, 1994b.

\section{AMERICAN SOCIETY FOR TESTING AND} MATERIALS - ASTM. Standard method of accelerated laboratory test of natural decay resistance of wood. ASTM D-2017. Annual Book of ASTM Standards, v.0410, p.324-328,1994c.

\section{BAINES, E. F. A laboratory technique to} measure the performance of preservative treated hardwood in ground contact. Stockholm: The International Research Group on Wood Preservation, 1982. 16p. (Doc. IRG/WP/2172).

BECKER, G. Método padrão sugerido pela IUFRO para ensaios de campo com estacas de madeira. Preservação de Madeira, v.1, n.4, p. 205-216, 1970 .

\section{CARBALLEIRA LOPEZ, G. A.; MILANO, S.}

Avaliação da durabilidade natural da madeira e de produtos usados na sua proteção. In: LEPAGE, E. S. (Coord.). Manual de preservação de madeiras. São Paulo: IPT, 1986. v.2. p.473-521.

\section{CAVALCANTE, M. S. Deterioração} biológica e preservação de madeiras. São Paulo: IPT, 1982. 40p. (Pesquisa e Desenvolvimento, 8).

DRYSDALE, A. J. Comparison of the effect of different soil sources on the type and rate of decay of $\mathrm{CCA}$ - treated pine exposed in a soil-bed. Stockholm: The International Research Group on Wood Preservation, 1984. 9p. (Doc. IRG/WP/2213).

HUNT, G. M.; GARRATT, G. A. Wood preservation. 3.ed. New York: McGraw Hill, 1967. 433p.

JOHNSON, G. C.; THORNTON, J. D.; GREAVES, $H$. The accelerated field simulator (fungal cellar). Stockholm: The International Research Group on Wood Preservation, 1982. 9p. (Doc. IRG/WP/2170).

R. Árvore, Viçosa-MG, v.33, n.3, p.511-520, 2009 
MAINIERI, C.; CHIMELO, J. P. Fichas de características das madeiras brasileiras. São Paulo: IPT, 1989. 418p.

McKAIG, P. A. Factors affecting decay rates in a fungus cellar. Stockholm: The International Research Group on Wood Preservation, 1985. 9p. (Doc. IRG/WP/2242).

PAES, J. B. Efeitos da purificação e do enriquecimento do creosoto vegetal em suas propriedades preservativas. 1997. 143f. Tese (Doutorado em Ciência Florestal) Universidade Federal de Viçosa, Viçosa, MG, 1997.

PAES, J. B. et al. Resistência natural de nove espécies de madeiras do semi-árido brasileiro a cupins subterrâneos, em ensaio de laboratório. Cerne, v.9, n.1, p.36-47, 2003.

PAES, J. B.; MORAIS, V. M.; LIMA, C. R. Resistência natural de nove espécies de madeiras do semi-árido brasileiro a cupins subterrâneos em ensaio de preferência alimentar. Brasil Florestal, v.20, n.72, p.59-69, 2001.

PAES, J. B.; MORAIS, V. M.; LIMA, C. R. Resistência natural de nove espécies de madeiras do semi-árido brasileiro a fungos xilófagos em condições de laboratório. Revista Árvore, v.28, n.2, p.275-282, 2004.
PAES, J. B.; MORAIS, V. M.; LIMA, C. R. Resistência natural de nove espécies de madeiras do semi-árido brasileiro a fungos causadores da podridão-mole. Revista Árvore, v.29, n.3, p.365-371, 2005.

PAES, J. B.; MORAIS, V. M.; LIMA, C. R.

Resistência das madeiras de aroeira (Myracrodruon urundeuva), cássia (Senna siamea) e ipê (Tabebuia impetiginosa) a fungos e cupins xilófagos, em condições de laboratório. Floresta e Ambiente, v.9, n.1, p.135-144, 2002.

PARAÍBA. PNUD/FAO/IBAMA/UFPB/GOV. Diagnóstico do setor florestal do Estado da Paraíba. João Pessoa:1994. 84p.

STEEL, R. G. D.; TORRIE, J. H. Principles and procedures of statistic: a biometrical approach. 2. ed. New York: Mc Graw-Hill, 1980. 633p.

VINDEN, P.; SAVORY, J. G.; DICKINSON, D. J.

Soil-bed studies. Stockholm: The International Research Group on Wood Preservation, 1982. 15p. (Doc. IRG/WP/2181).

WILLEITNER, H. Laboratory tests on the natural durability of timber: methods and problems. Stockholm: The International Research Group on Wood Preservation, 1984. 11p. (Doc. IRG/WP/2217). 